Welch, Nikki and Ana Tominc (forthcoming): Is Wine Consumption in Britain Democratizing?

Communicating Class and Taste through the Saturday Times Wine Column (1982-2017). Social Semiotics.

FINAL ACCEPTED COPY - Please consult the published version when citing To appear in Social Semiotics forthcoming

\title{
Is Wine Consumption in Britain Democratizing? Communicating Class and Taste through the Saturday Times Wine Column (1982-2017)
}

\begin{abstract}
:
The popularisation of wine drinking was one of the most significant changes in British drinking culture in the $20^{\text {th }}$ century, in terms of the increase in both the availability and acceptability of wine for the general population. Based on a discourse analysis of 35 years of Jane MacQuitty's Saturday Times Wine Column (1982-2017), this paper argues that while wine has been discursively constructed as a drink of the many, the distinction traditionally associated with wine drinking in Britain remains. The data demonstrate how MacQuitty constructs wine through the media stylistically as everybody's drink, while also constructing and maintaining a distinction between 'us' as an in-group whose wine knowledge and taste are distinct from 'them'.
\end{abstract}

Key Words: class, lifestyle, distinction, language style, wine columns, Jane MacQuitty

\begin{abstract}
About the Authors:
Nikki Welch studied Economics and Languages at the University of Surrey and subsequently completed the MSc in Gastronomy at Queen Margaret University. She has spent the last 17 years working in the commercial wine industry and now runs her own business demystifying wine,
\end{abstract}


Welch, Nikki and Ana Tominc (forthcoming): Is Wine Consumption in Britain Democratizing? Communicating Class and Taste through the Saturday Times Wine Column (1982-2017). Social Semiotics.

whisky and beer for consumers through events, staff training, videos and the use of her WineTubeMap, WhiskyTubeMap and BeerTubeMap. She is a published author of three books and writes regularly for non-academic publications. Contact nikki@ winetubemap.co.uk.

Ana Tominc is a lecturer and researcher at Queen Margaret University Edinburgh, Centre for Communication, Cultural and Media Studies. She teaches on food, culture, and communication as part of the postgraduate program MSc Gastronomy. She is interested in discourses of everyday life, specifically food and how it is represented and communicated in the media. She has published on celebrity chef discourse and globalization, discursive construction of identity via food, and food programs on the socialist television. Contact atominc@qmu.ac.uk. 
Welch, Nikki and Ana Tominc (forthcoming): Is Wine Consumption in Britain Democratizing?

Communicating Class and Taste through the Saturday Times Wine Column (1982-2017). Social Semiotics.

\section{Introduction}

The popularisation of wine drinking was one of the most significant changes in British drinking culture in the $20^{\text {th }}$ century. In the past, wine had been imported to Britain as a luxury good, hence symbolic boundaries were drawn between those who were able to afford it and those who could not; and between those who were able to demonstrate their connoisseurship and those who could not (Bourdieu 1984, Mennell 1985, Lamont 1992). Since the 1950s, however, what was once the drink of the affluent became more available for consumption by the majority of the population (Nicholls 2011; Ritchie 2007; Wehring 2012), owing much to increased access to supermarkets, the introduction of off-licensed retail outlets and changing social attitudes towards wine, such as the increasing popularity of wine-drinking amongst women and the acceptability of drinking wine without a meal (Howland 2013; Demossier 2010; Ritchie 2011). The lifestyle-based individually-oriented consumption patterns of the last decades have also taken over much of the traditional, class embedded tastes that used to be the dominant social dimension in the past (Warde 1997, Bourdieu 1984), resulting in the consumption of wine across classes.

One of the factors which accompanied this trend was the increasing availability of media advice related to wine consumption; from the early 1960s (in the US from the 1940s), newspapers, such as in Britain the Sunday Times, started to offer their audiences advice about what wine to choose, how to combine it with food, and how to serve it (Reichl 2007). This kind of lifestyle advice, where the audience was advised about ways to go about self- improvement, was part of a media trend to promote the communication and consumption of everyday lifestyles in Western, postmodern societies, where tradition was no longer the only guide to life (Lewis 2008; van 
Welch, Nikki and Ana Tominc (forthcoming): Is Wine Consumption in Britain Democratizing? Communicating Class and Taste through the Saturday Times Wine Column (1982-2017). Social Semiotics.

Leeuwen 2005). Instead, the media was becoming a seminal site for the dissemination of advice about the consumption of goods, services and experiences, offering everybody the "opportunity to 'make over' our lives and ourselves" (Bell and Hollows 2006, 4). Therefore, the opportunity that the media, and in this case wine columns in particular, seemingly offer to audiences regardless of class boundaries is in line with what Johnston and Baumann $(2015,161-170)$ refer to as foodie discourse. This concept demonstrates how the erosion of class distinction in contemporary Western societies is maintained through promoting the "equality of inequality" and reducing privilege to ordinariness. Both create an image of the foodie as an omnivore: rejecting snobbery in return for the image of a classless, all-eating consumer. Despite this, wine consumption remains a sign of distinction, since it is through an "individual's openness to a range of [culinary] experiences" rather than the exclusiveness of particular tastes or choices that sections of society display culinary capital ${ }^{1}$. As Naccarato and LeBesco $(2012,9)$ maintain, "[t]hose who seek out the greatest variety of tastes and who are open to the broadest range of experiences emerge as the most culturally capitalized." Such covert elitism (ibid., p. 11) is communicated through the (lifestyle) media where individuals with access to power (i.e. Bourdieu's (1984) cultural intermediaries) are able to promote certain desirable tastes, including wine choices, to a mass audience making them generally acceptable tastes (see also Peterson and Kern 1996).

$1 \quad$ As we argue in this paper, however, there is a maintenance of both democratization and exclusivity when it comes to wines, i.e. only specific groups drink certain wines, while there is a push for democratization of wine drinking/increase in cultural capital through the media, such as the wine column. 
Welch, Nikki and Ana Tominc (forthcoming): Is Wine Consumption in Britain Democratizing? Communicating Class and Taste through the Saturday Times Wine Column (1982-2017). Social Semiotics.

In this sense, newspaper wine columns are perfect place where popular tastes relating to wine can be shaped. Intended for a mass audience, they complement the seemingly impenetrable wine guides developed for professional use by the wine industry itself. The tasting note, as the genre of the professional wine tasting report is called, was developed in an attempt to standardize and give credibility to the wine profession through the institutionalization of language. Through it, a wine's characteristics were to be described and evaluated in what was originally meant to be an objective assessment of a wine (Shesgreen 2003; Silverstein 2004; Lehrer 2009). As a result, the language of the tasting note, designed to tackle the subjective complexities of the taste, smell and look of wine, arguably requires expert knowledge, since wine characteristics, including nuances, need to be described using agreed nominators, such as Noble's aroma wheel or the WSET Systematic Approach to Tasting Wine (Noble 1990; WSET 2014). While such "winespeak" may usefully draw attention to qualities wine drinkers may not have otherwise noticed (Lehrer 2009), engagement in "winespeak" is often also seen as a method of differentiation, demonstrating status and expert knowledge (Howland 2013).

In this paper, we, however, focus on the newspaper column of one of Britain's leading wine writers, Jane MacQuitty, who has been writing columns for the Saturday Times for more than 35 years. Starting her journalistic career as the wine and food correspondent for House \& Garden magazine and later on as an editor of the Which? Wine Guide, published by the Consumers' Association, she became the Wine Correspondent and Drink Correspondent for The Times newspaper in 1982. Her columns are influential. She is regularly credited with "selling-out" a particular wine through a mention in her column, although this is a feature of wine columns in general. The inclusion of a specific wine as a recommendation in one of the mainstream 
Welch, Nikki and Ana Tominc (forthcoming): Is Wine Consumption in Britain Democratizing? Communicating Class and Taste through the Saturday Times Wine Column (1982-2017). Social Semiotics.

newspapers can result in a 4,000\% sales increase (Joseph 2009). It is therefore surprising that unlike the more professionally-oriented tasting note, newspaper lifestyle-oriented wine columns have received very little, if any, academic attention, even often being dismissed as irrelevant (Silverstein 2004; Bender 2008).

Unlike tasting notes, which are familiar only to the few who specialise in evaluating wine as a profession, MacQuitty's wine columns introduce the reader to the world of wine through language that is much more familiar to the ordinary reader, offering anecdotes from her own life and advice on how to go about drinking wines from first hand experience. Although clearly an expert, she often switches her identity from that of a wine connoisseur to a much more approachable ordinary consumer, through whose eyes she not only recommends wine, but offers an illusion of wine democratization where wine is represented as the drink of choice that is approachable and accessible to the non-expert reader. In this context, then, and relying on an analysis of thirty-five years of MacQuitty’s wine columns, we ask how she linguistically constructs an image of wine as a democratized, non-elite product, while at the same time offering herself as an expert guide to wine as a high-class drink. Differently to the tasting note, which constructs expertise through expert vocabulary ultimately leading to 'educated connoisseurship', the wine column aims to discursively democratize wine for a broader audience, who may have very little expertise in wine, while still retaining a touch of class. We are thus aiming to add to the growing corpus of research on food and language (on wine, specifically Hommerberg 2011; generally e.g. Gerhardt, Frobenius and Ley 2012; Jurafsky 2014; Riley and Paugh 2019 to mention but a few), and in particular to the body on the construction of class and lifestyle through food discourse that has recently attracted some attention (cf. Tominc 2017, for an 
Welch, Nikki and Ana Tominc (forthcoming): Is Wine Consumption in Britain Democratizing? Communicating Class and Taste through the Saturday Times Wine Column (1982-2017). Social Semiotics.

analysis of class and lifestyle through cookbooks, Mapes 2018, for foodie discourse as elite discourse).

This paper is divided into three parts; first, we offer the theoretical background to the issues around class, taste and language, a section which is followed by a brief note discussing method and data. The empirical part of the paper consists of two parts; first, we show how MacQuitty constructs wine as the everyday popular choice of drink for every lifestyle, while the second part shows the opposite - how she at the same time constructs a clear distinction between "us" who know about good wine and "them" who do not. 
Welch, Nikki and Ana Tominc (forthcoming): Is Wine Consumption in Britain Democratizing?

Communicating Class and Taste through the Saturday Times Wine Column (1982-2017). Social Semiotics.

\section{Construction of class and lifestyle through the language style of wine columns}

Values and identities, such as class, are communicated and constructed through language style by drawing on specific language variants and their combinations, also understood as "composites of connotations" (Fairclough 2000, 14; Machin and van Leeuwen 2005). As lifestyles are constructed by drawing on various styles found in everyday lives, language styles, similarly, draw on a variety of linguistic styles, such as advertising or conversational style, to create particular, identity related styles (Machin and van Leeuwen 2005). One of the consequences of this process is the blurring of genres. New, hybrid genres are now built of various styles, often transgressing boundaries of discourses, a feature defined by Fairclough as interdiscursivity, one of the cornerstones of postmodern consumerist discourse, where discourses, such as advertising, can be intertwined in new relationships outside of their traditional boundaries and genres (Fairclough 2010; Bax 2010). At its core, advertising is associated with selling products and services, although its uses beyond selling have come to also relate it to giving meaning to consumer goods and identity formation (van Leeuwen 2005, 150). It is widely accepted that the linguistic styles developed by advertisers to promote and sell products and services have been adopted by many other genres and industries to persuade the reader not just to buy an item but also to identify certain values with it (Van Leeuwen 2005; Fairclough 2000).

As we will demonstrate in the following, advertising and genre blurring became an increasingly visible feature of wine columns as they approached the new millennium. Like other lifestyle media, the wine column increasingly employed various styles of language to communicate an overall feeling of the accessibility of wine by, on the one hand, employing the accepted language 
Welch, Nikki and Ana Tominc (forthcoming): Is Wine Consumption in Britain Democratizing?

Communicating Class and Taste through the Saturday Times Wine Column (1982-2017). Social Semiotics.

of tasting notes intended for a specialist audience, while, at the same time, promoting a language style that is closer to the everyday reader. Often, it presents itself in the form of an opinion column featuring a more varied content including biography, cultural and historical information as well as advice (Hanke 1989). Not only has every separate section of a wine column its own language style, but various styles of language are blended in all of them, creating a unique wine column text type which has a distinct format and style to that of the tasting note and constitutes a unique genre within the discourse of wine.

Relying on Bourdieu's work, Tominc (2017, 21), however, argues that this kind of construction of language styles can never be an unlimited project, as much linguistic lifestyle work rooted in theories of postmodernity seems to suggest. Instead, in line with Bourdieu's concept of habitus, a defining feature of class and taste, lifestyle cannot be separated from the underlying structures, such as class, that limit and shape possibilities of lifestyle choice. Just as knowledge and display of language variants, such as standard language and dialect, suggest high or low linguistic capital and with this, communicate distinction or lack of it (Bourdieu 1977), "composites of connotations" construct lifestyles that unavoidably reveal the habitus and cultural capital of those responsible for the production (and at the same time also reception) of texts. Hence, through this hybridity and interdiscursivity of text, MacQuitty's wine columns speak as much of herself and of the Saturday Times, whose editorial policies around lifestyle writing they comply with, as about their readership - aspirational, advice-seeking wine enthusiasts, whose preferences matter not only to MacQuitty and the newspaper, but to the wine business itself. 
Welch, Nikki and Ana Tominc (forthcoming): Is Wine Consumption in Britain Democratizing?

Communicating Class and Taste through the Saturday Times Wine Column (1982-2017). Social

Semiotics.

\section{Data and Method: thirty-five years of Jane MacQuitty's Wine Column in the Saturday Times}

This study is based on an analysis of wine writer Jane MacQuitty's wine columns, published in the Saturday Times between 1982 and 2017, covering 35 years of wine column writing in this highly influential British quality newspaper. The full corpus, which contains 1,820 wine columns, that is one per week over 35 years, has been narrowed down systematically, with the aim of creating a corpus that would allow a more detailed language analysis, but would be at the same time representative of the full corpus. We hypothesized that the representations of wine are seasonal, and thus selected columns from the first week in May and the first week in December of every other year, allowing for general summer and more specific Christmas columns to be included into the corpus (Mautner 2008). This is because the theme of the main body of the texts shifts depending on the season, with the December articles focusing on gifting and Christmas whilst the May articles have a more eclectic thematic structure, sometimes focusing on season and occasion and other times on industry. ${ }^{2}$ The final corpus reduced in this way contained 34 wine columns, which were analysed systematically for language style, in terms of various categories, based on an extended version of van Leeuwen's language style guide (2005), namely advertising style, expert style, and conversational style.

2 The coding for the columns, seen in the later sections, reflects this selection, hence the code 050582 refers to the column published on 5 May 1982. 
Welch, Nikki and Ana Tominc (forthcoming): Is Wine Consumption in Britain Democratizing? Communicating Class and Taste through the Saturday Times Wine Column (1982-2017). Social Semiotics.

Although several influential authors now write about wine, the choice to focus on only one through an extended period was made deliberately, so as to reduce the influence of individual style on the overall writing style. As Machin and Van Leeuwen $(2003,494)$ find, uses of styles of writing analysed in this paper are not unique to specific magazines or authors; instead, they "form part of a wider cultural and ideological trend within neo-capitalism," demonstrating an overall change in the ways through which the media communicates: our analysis merely demonstrates the trend through the lens of the wine column. 
Welch, Nikki and Ana Tominc (forthcoming): Is Wine Consumption in Britain Democratizing?

Communicating Class and Taste through the Saturday Times Wine Column (1982-2017). Social

Semiotics.

\section{Wine as Everybody's Drink: Democratization of wine consumption through language style}

\subsection{An Overview of MacQuitty's wine column (1982-2017)}

Changes in wine column language style reflect changes in the consumption of wine and also parallel the growth of lifestyle advice in the media, as mainly expert advice transforms into mainly lifestyle-oriented advice. The format of the early 1980s articles is primarily an expert piece with a headline, main body and a number of recommendations within it. Here, the wine column is a small section of text with no illustrations that is yet to adopt much of the advertising or conversational style of the later editions. Wine names and descriptions are included as part of the main body. The recommendations either sit in the flow of the paragraph to illustrate a point or may form a list placed towards the end of the article to direct readers to good examples of the wines. Their inclusion appears to be coherent to the theme and is non-intrusive to the reading of the article.

The main body becomes more visible during the 1990s, with a longer word count, more complex content and an illustration. In the 2000s, attention shifts to the headline, illustration and a separate section for the wine recommendations with a fluctuating amount of space given to the main body. This separate wine recommendation area grows in importance both in the space given to it and through the way it is separated off (e.g. the size of photographs of bottles and the overall balance between main body and wine recommendations). Highlighted photos of the relevant bottles appear in 1994 and these grow in size and prominence. In that year, the introduction of the serialised 'Top 100 Wines' changes the format replacing the main body with 20 or 25 wine recommendations as part of a four-week series highlighting the best value in 
Welch, Nikki and Ana Tominc (forthcoming): Is Wine Consumption in Britain Democratizing?

Communicating Class and Taste through the Saturday Times Wine Column (1982-2017). Social

Semiotics.

different price categories. ${ }^{3}$ A variety of language styles starts to be used to reinforce or direct the attention of the reader to certain values and construct the appearance of democratization through the thirty-five years under study, with a greater use of more conversational and less expert style occurring towards the 2000s.

\subsection{Advertising style}

Advertising style, at the core of much of contemporary lifestyle writing as discussed above (e.g. Machin and van Leeuwen 2003; 2005), is based on various linguistic devices through which products and services are presented to the consumers in a persuasive way. Within this study we will focus on those that are the most prominent in the corpus: direct address, use of figurative language and poetic devices, although conversational language and various language variants analyzed in other sections can also be seen to be a part of advertising language (van Leeuwen 2005; Myers 1994). Through these, advertisers gain attention of consumers, while also ensure consumers remember and identify with the offered products. The diachronic analysis of the corpus shows a growing use of advertising techniques throughout all of the elements of the column. It may be possible to argue that this is purely a symptom of the newspaper remodelling its style to generate advertising revenue and therefore needing to justify its importance by demonstrating a tangible link between a product featuring in the newspaper and sales. However,

3 As the wine column shifts its position in the newspaper from the body of the actual newspaper to a supplement and later a magazine, this clearly influences the visual styling of the column. This switch happens around the year 1990 and is an indication of a wider trend in newspapers to generate revenue through advertising, replicating the formula of glossy magazines. Wine continues to be featured alongside food, fashion, travel and home, as it was in the newspaper format but the increase in space and change in the style of presentation demonstrates a wider change in the genre of lifestyle. 
Welch, Nikki and Ana Tominc (forthcoming): Is Wine Consumption in Britain Democratizing?

Communicating Class and Taste through the Saturday Times Wine Column (1982-2017). Social Semiotics.

the language permeates beyond specific products into the main body suggesting a subtler link positioning wine as a marker for certain identities and values.

\subsubsection{Constructing and addressing the audience}

The use of direct address, through which advertising seeks to address its audience directly, appears throughout the corpus in a number of ways, changing over time from a prescriptive to a more inclusive instruction. The articles from the early 1980s include phrases as seen in (1) which demonstrate a direct suggestion from author to reader about who the reader might be and what he/she should drink. The article acknowledges the situation the reader may be in by suggesting that they are not alone in looking for specific wines on the market.

"With the party season approaching many people are on the lookout for wines that are capable of putting friends in a good mood - but at rock bottom prices... Do also try Cullen's two litre Austrian party wine...” 041282

In other articles, readers are identified specifically, as "claret officianados" (061286), "sweettooths" (031294) or "sub £4ers" (030508), which constructs them in terms of their wine preference (liking specific wine varieties, sweet wine, or those below £4) and allows for the writer to offer recommendations based on their personal preferences. The December articles in the corpus often paint a picture of someone who is behind with their Christmas preparations using direct questions and instructions as demonstrated in (2). To them, MacQuitty offers reassurance that everything will be fine if they follow her advice. 
Welch, Nikki and Ana Tominc (forthcoming): Is Wine Consumption in Britain Democratizing?

Communicating Class and Taste through the Saturday Times Wine Column (1982-2017). Social Semiotics.

"FRET NOT. Three weeks to go until Christmas Eve and still without presents posted, purchased, or even planned?" 031294

This individualisation of advice suggests that the writer is non-judgemental towards specific wine choices. By creating different realities for different consumer groups she is then able to give instructions using the imperative tense when directly discussing the wines (Lewis 2008). Phrases like "buck the trend by buying” (020592), “...move sharpish to pick up” (060500) and "snap it up" (030508) feature prominently giving a direct call to action. In the main, they add an element of speed or exclusivity to the action by suggesting a wine will sell out or a deal will end and the reader will miss out. This element is inherently persuasive and linked to the concept that the column has a value linked to wine sales, a feature which is at the core of advertising.

\subsubsection{Communicating taste of wine: Figurative language and poetic devices}

\section{Figurative language in wine writing}

Figurative language is commonly understood to include stylistic devices that transfer meaning, such as metaphors, metonymy and synecdoche, which all speak of one thing in terms of something else (Leech 1969). In advertising, they are used to associate a product with an idea or value outside of its normal sphere, an idea linked to the concept of intertextuality (Van Leeuwen 2005; Fairclough 1992). This role of figurative language, and particularly of metaphor, is integral to wine writing in general, with layers of figurative language allowing the writer to communicate 
Welch, Nikki and Ana Tominc (forthcoming): Is Wine Consumption in Britain Democratizing? Communicating Class and Taste through the Saturday Times Wine Column (1982-2017). Social Semiotics.

a complex sensory experience and creating a shortcut for the reader to engage with the wine (Caballero 2007; Creed 2014; Eliot 2006), particularly so, since - as Korsemeyer $(2007,3)$ writes - "variability of 'subjective' experience is nowhere more noticeable than with the sense of taste."

Figurative language mainly takes the form of metaphor. Wine taste and smell descriptions are intrinsically metaphorical, indicating that the wine under consideration has properties similar to other foods, for example, a wine can be described as being citrus or citrusy or like a fruit, i.e. grapefruit-like (Lehrer 2009). These descriptions can be systematically applied and in general make sense to the reader because their points of reference are very familiar (Silverstein 2004; Caballero 2007; Lehrer 2009, for systematic research into the language of winespeak, see Lehrer 2009; see also Caballero 2007, Creed 2014, Caballero and Suarez-Toste 2008). ${ }^{4}$

However, the source domains drawn on also extend to tastes and flavours that are less recognisable as consumables, such as tar, iodine or petrol. Wines do not contain these flavours, merely properties similar to those descriptors, but the description is written as if they actually do. Here the reader is expected to make the connection with the subject through a more abstract process. Beyond these taste and flavour metaphors is a more abstract layer of figurative language used to communicate an overall sense of the wine rather than just its sensory elements (Shesgreen 2003; Caballero 2007; Lehrer 2009).

4 Whilst most argue the importance of figurative language in winespeak to communicate the complex and sensory nature of the process, some critics claim that the use of metaphors is unnecessary or an affectation (Gluck 2003; Bender 2008). Parallel to this runs the claim that wine writing, be it analytic or synthetic, is only ever subjective. Most experiments to test this theory arrive at the conclusion that not all experts can consistently describe and identify wines from descriptions and even fewer non-experts are able to do so (Lehrer 2009; Langlois et al. 2011; Mouret et al. 2013). 
Welch, Nikki and Ana Tominc (forthcoming): Is Wine Consumption in Britain Democratizing? Communicating Class and Taste through the Saturday Times Wine Column (1982-2017). Social Semiotics.

Three kinds of metaphors have been recognized to describe wine, namely anthropomorphic metaphors, where the wine is given human properties or characteristics which the wine is described as possessing or being like; structural or 3D metaphors where the wine is described as a building or structure (e.g. well-built, rigid or robust); and textile metaphors where details of the texture and mouthfeel are provided (e.g. velvety or silky). This prevalence of metaphor, and particularly those using manner of motion verbs (Caballero 2007) ${ }^{5}$, is believed to be linked to the multi-sensory nature of the experience of wine, for which the English language does not have a specialised vernacular (Caballero 2007; Lehrer 2009; Aitchison 2012; Creed 2014), a characteristic shared with other categories such as art, music and theatre. The dynamic nature of metaphor, reinforced by manner of motion verbs, communicates an experience through which the consumer passes (Caballero 2007).

Although it may well be argued that the use of metaphor in the genre of the wine column simply reflects tasting note vocabulary and its evolution, the corpus evidence shows that there is generally a growing use of figurative language in the wine column over the period, in both the wine descriptions and in the main body of text. The main trend in the wine recommendations is a move from fairly standard language towards a more figurative style. Some of these differences

5 The metaphors are not purely constructed using adjectives, Caballero (2007) also identifies the use of 'manner-of-motion' verbs as a key element of winespeak as demonstrated in the use of 'heaves' in 080504.. These verbs are more commonly used in English than other languages, and describe the manner of the verb within the verb itself. For example the verb tiptoed describes what most other languages would describe as 'walking on tiptoe'. Also note that although this is a common feature of wine tasting notes, it is far less common in MacQuitty's wine columns. 
Welch, Nikki and Ana Tominc (forthcoming): Is Wine Consumption in Britain Democratizing?

Communicating Class and Taste through the Saturday Times Wine Column (1982-2017). Social Semiotics.

do reflect the evolution of the language of the tasting note (Lehrer 2009), with more human characteristics and architectural metaphors used to describe wines alongside the increase of manner-of-motion verbs as in (3).

(3) “...makes a fine festive white, as its heady, perfumed, fruit-cocktail charged flavours cope with the big-food assault course in a way that skinny, bone-dry whites just don't." 061208

\section{Figurative language specific to wine columns}

However, there are also other elements that seem to be distinct to the wine column genre. These are the use of metaphors that are borrowed from recipes or food descriptions, and those used to create an atmosphere or occasion. MacQuitty's use of food metaphors become increasingly frequent across the study, perhaps a reflection of the growing importance that food plays in today's lifestyle values. This could be broken down into the sheer variety of food metaphors that are used to describe wine, from an extensive list of fruits, meats, vegetables and spices to more specific similes equating a whole wine with a food rather than just a flavour, as depicted in (4). Perhaps even more interesting is the introduction of composition of the wine being described as if it is part of a magazine recipe. This is possibly another example of the intertextuality of the genre, using the code of the recipe to help the reader understand the make-up of a wine rather than the approaches employed in the use of expert style, as seen later. In this way, wine-making is made a more familiar and approachable subject to the reader. This adoption of the genre of food writing could also be an attempt (conscious or not) to transfer some of the growing cultural 
Welch, Nikki and Ana Tominc (forthcoming): Is Wine Consumption in Britain Democratizing?

Communicating Class and Taste through the Saturday Times Wine Column (1982-2017). Social Semiotics.

capital associated with food (Naccarto and Lebesco 2012; Johnston and Baumann 2010) or to borrow its 'diversion' values (Rousseau 2012).

“1997 L’Esprit de Chevalier Pessac-Léognan... an impressive cabernet sauvignon with a dollop of merlot and a dash of cabernet franc ... 2001 Coyam...This burly red, made from one third cabernet sauvignon and merlot, topped up with carmenère and syrah plus a smidgin of mourvèdre...2002 Montes Alpha Syrah...lots of guts, spice and berry fruit, topped with black pepper and chocolate, the vinous equivalent of an ice-cream sundae..."041204

The figurative language within the wine column demonstrates some of its complex intertextuality and the range of values and identities it models both within the confines of winespeak and beyond. The introduction of the food elements particularly highlights a move away from some of the earlier themes focused on the wine industry to speak the language of the broader audience where food has specific cultural capital and a shared value set. Equally, using figurative language to create a sense of occasion supports the notion that it is a certain occasion itself that carries some of the social value of wine, rather than merely wine and its connotations. Outside the wine recommendations in particular, a more consistent use of figurative language is found throughout the corpus that paints a picture of the occasion or lifestyle with which the themes would resonate. This ties into the research conducted by Ritchie (2011) that wine carries different social capital on different occasions.

\section{Poetic devices}


Welch, Nikki and Ana Tominc (forthcoming): Is Wine Consumption in Britain Democratizing?

Communicating Class and Taste through the Saturday Times Wine Column (1982-2017). Social Semiotics.

Devices such as rhythm, assonance and simile have generally been analysed as part of literary language, although they are also common in non-literary genres. In the wine columns, there are often lists of three or more adjectives used that often mix similes, particularly using the '-y' and 'like x' formats. While tasting notes break down aroma, flavour, texture and finish, these descriptions focus on an overall sense of the wine. Three examples, (5), (6), and (7), show the list construction along with a blend of simile and metaphor in both style and flavour descriptions. “...this' '92 is full of intense, sweet, toasty, buttered popcorn and butter-biscuit style." 071296

(6) “...give this impressive, fat, chocolatey, plum, game and spice-laden Portuguese red a whirl." 041204

(7) “...from the now tiring '06 white French vintage to the young, perky '07s, such as this precocious, peardrop and pineapple-laden, colombard grape-dominant Gascon white...". 030508

These structures bring to mind the poetic devices often used in advertising to add interest, memorability and entertainment, which are not reflective of every day speech (Van Leeuwen 2005; Myers 2006). In (8) and (9), MacQuitty uses poetic devices including alliteration and metaphor to evoke a mood of place and to put the reader in it, therefore attaching a high social value to the wines she mentions later. 
Welch, Nikki and Ana Tominc (forthcoming): Is Wine Consumption in Britain Democratizing?

Communicating Class and Taste through the Saturday Times Wine Column (1982-2017). Social Semiotics.

(8) “... Instead, summon up summer in a glass with pink fizz, toothsome Teutonic garden whites, champagne and bargain bottles from Eastern Europe and sunny Australia..."020592

(9) "Summer is almost upon us and the burgeoning of buds, dawn chorus and engagement columns mean only one thing to me; the start of the sparkling wine season..." 020598

This section demonstrates the relevance of advertising style to the genre of the wine column. It illustrates the use of direct address to persuade the reader to take action by identifying with them and giving them a direct call to action while also demonstrating that they can engage with wine as a non-exclusive product. It also discovers the use of figurative language, beyond winespeak, which includes poetic devices and metaphors, particularly from the food world, to create an approachable, safe world, which the reader can identify with and which reinforces the value that wine shares with certain occasions and its culinary capital.

\subsection{Conversational Style}

Tannen (1987: 251) defines conversational style as "the way meaning is encoded in and derived from speech." The separation of conversational and advertising styles, however, may not be as straightforward as van Leeuwen presents it in his style analysis, since language styles in general can be used to attract audience attention and increase memorability of the product advertised (Myers 1994). They are also often adopted in order to create an illusion of equality between 
Welch, Nikki and Ana Tominc (forthcoming): Is Wine Consumption in Britain Democratizing?

Communicating Class and Taste through the Saturday Times Wine Column (1982-2017). Social Semiotics.

parties who are not traditionally equal (Lewis 2008). The evidence here seems to suggest such use is acting as a device to reinforce the values of good taste and identities promoted by MacQuitty by bringing the reader discursively closer. MacQuitty frequently also adopts a conversational style throughout the columns, switching from the detached voice of the expert or advertising voice to a more friendly, inclusive text that constructs her as 'one of us', bringing the reader close through a style of speech that is supposedly close to the way audience uses it conventionally. In doing so, she creates a sense of the reader and MacQuitty as being one and the same, sharing values and distancing those who might be dissimilar (El Saj 2012; Harwood 2005).

\subsubsection{Creating intimacy and an in-group through the use of pronouns}

Through the use of the personal pronoun "I" the reader is made to feel privy to elements of the writer's personal life with references to home, family and personal views. MacQuitty brings more of her own personal opinions to the wine recommendations, for example, "I loved its fine fruity scent...” (070588) and “...as well as an intense fruit-and-wax finish. Heaven!” (071296). Both give a very personal take on the wines, which is a distinctly different style to the objective tone of the tasting note. These show the human, non-expert side of Jane MacQuitty and create intimacy between the reader and the writer. Some information that she shares is very personal in nature, and it could be argued, even controversial, such as (10), where she openly admits to drinking alcohol while pregnant, a British public faux pas:

(10) Having just given birth to a third healthy child in three years, I am entirely convinced of the merits of moderate wine consumption while pregnant." 140594 
Welch, Nikki and Ana Tominc (forthcoming): Is Wine Consumption in Britain Democratizing?

Communicating Class and Taste through the Saturday Times Wine Column (1982-2017). Social Semiotics.

Over time, the relationship between MacQuitty and the reader appears to change and in the later columns, after 2002, an increasing use of the pronoun "us" and "we" is particularly noticeable, although in both 'inclusive' and 'exclusive' senses (Harwood 2005; Reisigl and Wodak 2001). "Few of us have homes with cellars but this should not deter you from storing some choice bottles. I live in a centrally heated flat and most of my wines are stored there without ill effect." (081290) and "The more sensible among us attend our children's parties, have a guest list, check arrivals at the door, and issue two drinks vouchers per head for the entire event." $(060506)$ portray MacQuitty as having a modest lifestyle sharing the same concerns as her audience, as is demonstrated in 060506 where she discusses how to manage alcohol at teenagers' parties from the perspective of a parent. This could also be used to encourage the reader to adopt a certain moral stance and practical strategies to cope with contemporary problems.

This construction of an in-group that removes the sense of social difference between MacQuitty and reader by assuming, via the rhetorical use of "us" that they share the same values (Fairclough 1989), results in an assumption that they are not only equal, but that they share a level of intimacy where personal information can be exchanged; it constructs a synthetically personal relationship that only exists on the pages of the wine column (Fairclough 1992).

\subsubsection{Creating equality through less formal language}

A key element of conversational style is the use of less formal language, featuring idioms, slang, compounds and regional dialect (Van Leeuwen, 2005). These appear throughout the texts in an inconsistent manner, and there seems to be no rationale to when they are used, unlike other 
Welch, Nikki and Ana Tominc (forthcoming): Is Wine Consumption in Britain Democratizing?

Communicating Class and Taste through the Saturday Times Wine Column (1982-2017). Social Semiotics.

elements that become more or less important over time. MacQuitty uses a number of well-known idioms in her pieces, in (11), two idioms, much closer to speech than written text:

(11) “...My own recent tasting notes show that you need to kiss a lot of frogs before you find a single prince among southern French wines... But the news that an allpowerful, all-controlling French wine authority combining the independent Languedoc, Roussillon and vin de pays groups has been formed and dreamt up the new inclusive Sud de France sunshine logo gives me the heeby jeebies. "030508

Readers would have to understand the idioms and their relevance to be able to understand her meaning and identify with them. As these are well-established turns of phrases it is likely that readers barely notice them and respond easily to the chatty style. Some are even more extreme, as in example (12), where the tone is far more conversational, and potentially controversial.

(12) "...if you and yours have served gut rot, none of your guests will thank you the next day when they wake with the mother of all hangovers." 020598

As is common in conversational and advertising styles, MacQuitty addresses the reader directly, putting them into a scenario (e.g. through a direct address 'you and yours'), before using the phrase 'gut-rot' to describe cheap wine and suggesting that the readers' guests will drink so much they will end up with a "mother of all" (terrible) hangover. This language is very colloquial and could be read as shocking in context by being juxtaposed with elegant summer parties. It could be suggested that this a device to avoid carrying too much distinction and to 
Welch, Nikki and Ana Tominc (forthcoming): Is Wine Consumption in Britain Democratizing? Communicating Class and Taste through the Saturday Times Wine Column (1982-2017). Social Semiotics.

remind the reader that the author is just a normal person who has parties where people end up with hangovers, giving the reader permission to do so themselves.

However, this is not the only type of colloquialism that is used in the corpus: many others can be found, such as the compounds " $t$ ' other" and "sweet'uns", used in the context of other more formal language like "finer still" and "teutonic" (100586). This use of local or informal language variants can increase the appeal to the audience as these compounds evoke northern English dialects in particular or working class language more vaguely.

Like advertising, the use of conversational style appears to offset MacQuitty's wine expert persona, by giving her a personality and character and making her accessible through shared language, a projection of shared means and lifestyle and an informal tone, thus creating the illusion of wine as a drink for everyone. 
Welch, Nikki and Ana Tominc (forthcoming): Is Wine Consumption in Britain Democratizing?

Communicating Class and Taste through the Saturday Times Wine Column (1982-2017). Social Semiotics.

\section{Wine Experts and the Rest: Construction of 'us' and 'them' in Wine Columns}

Despite the interdiscursive relations of these texts with advertising discourse and conversational style, which construct wine as the choice of everyday drink of the ordinary person, there is a parallel tendency to preserve the distinction between those who know ("us") and those who do not know ("them") most visible through this discourse via the inclusion of expert style, various linguistic variants and a construction of "us" and "them" categories. All of these maintain the distinction in terms of taste and lifestyle as there is an assumption that wine expertise and specific language variants are (or used to be) linked to a specific class. And while, as we have seen above, there is an effort to inclusively construct an in group, there is at the same time also a distinction between 'those of us' who do things in one way and those who do not. The use of expert style could be a way of reinforcing MacQuitty's role as guide to what is on trend, good quality or good value and ensuring her credibility in this role is maintained. It may also be a reflection of the notion of high status and complexity that has been attached to wine in the past and is a way of maintaining her status and distinction as an expert in it. MacQuitty appears to be a more traditional expert, who has a high level of technical knowledge, rather than an everyday expert, who has an aspirational lifestyle value (Lewis 2008). Expertise is constructed via the use of technical language, "winespeak" as a specific code (beyond vocabulary) of speaking and formal language.

\subsection{Technical language and "winespeak"}

Although similar in effect, technical language and "winespeak" differ in that the latter is what professionals refer to as a code to describe wine. The use of technical language is a key and 
Welch, Nikki and Ana Tominc (forthcoming): Is Wine Consumption in Britain Democratizing?

Communicating Class and Taste through the Saturday Times Wine Column (1982-2017). Social Semiotics.

obvious trait of expert style and the language of the main body of the text frequently moves in to either technical language about wine and winemaking or about the wine industry, thus demonstrating MacQuitty's specialised knowledge. This language is provided un-apologetically and the terms are given without further explanation, assuming readers' familiarity. Technical winemaking terms appear amongst some of the less formal language, although the latter still requires basic understanding of wine-making and maturing processes. (13) below is a reasonably common structure in the main body of the article where the use of the technical term 'coldfermentation' is used amongst a blend of tasting note terminology like 'lively' and quite basic descriptors like 'oaky'.

(13) "Although it is the lively, fresh, cold-fermentation white riojas which have, I believe, given Spain a place in the good white wine class, there are one or two oaky, traditional white riojas that deserve to be included..." 050584

This is relevant throughout the corpus; the May 2008 column (14), for example, covers the political challenges of the Languedoc region of France and discusses the viticultural, vinification, marketing and taste implications. To understand this fully the reader would have to understand the terminology of 'grubbing up' 'yields' and their implications.

(14) "No one would deny the improvements in the Midi over the past 20 years, including grubbing up dud vines, planting better ones and virtually halving yields to 16 million hectolitres..."030508 
Welch, Nikki and Ana Tominc (forthcoming): Is Wine Consumption in Britain Democratizing? Communicating Class and Taste through the Saturday Times Wine Column (1982-2017). Social Semiotics.

In the earlier May articles analysed (e.g. late 1980s and early 1990s) the main body is often dedicated to a technical theme, including the use of Sorbitol in wine production which concerns winemaking (050590), the performance of supermarket wine buyers in the Australian market which details the workings of the wine industry (070588) and the most recent Bordeaux vintage concerning technical aspects of the wine market (040596). The frequency of the use of a technical theme for a column diminishes over the period, perhaps reflecting a wider trend, moving away from traditional rules towards a more semiotic value set (e.g. referring to social styles) (Van Leeuwen 2005).

Contrary to her use of technical language, however, MacQuitty rarely follows the format of "winespeak" as a whole, although there are examples when her language reverts to something more akin to the tasting note, which, as discussed above, follows a relatively prescriptive structure, using industry-wide guides (e.g. WSET, Ann Noble's Wine aroma wheel, Gawel (2000)'s Mouthful wheel) that match the agreed tastes of wine to a linguistic denotator, which despite subjectivity of taste, needs to be learnt. ${ }^{6}$ In (15) below, the WSET hierarchy of nose and palate is followed as is the suggested terminology of "fresh" and "clean". “This Chardonnay's fresh, buttery scent and clean, fruity lime-lemon palate...”

031288

6 Despite this, Lehrer's (2009) research demonstrates that even professional wine description has changed in recent decades, increasing the use of and adding new metaphors through which wine is described. 
Welch, Nikki and Ana Tominc (forthcoming): Is Wine Consumption in Britain Democratizing?

Communicating Class and Taste through the Saturday Times Wine Column (1982-2017). Social Semiotics.

By adopting some of the tasting note genre, MacQuitty is both opening up the world to readers and in doing so potentially making it accessible to them, whilst at the same time reinforcing that there is an established code which should be used when discussing wine. It could be argued that this latter point creates a layer of distance between the reader and the wine. It should be noted that, in the main, her notes are more of a hybrid, and, given that there are only a limited number of ways to describe taste and flavour, the fact that her use of vocabulary is consistent with that used in a tasting note does not necessarily mean that readers will recognise the code.

\subsection{Use of formal language and distinction through construction of "us" and "them"}

MacQuitty uses a variety of styles of address throughout the texts, and her use of formal language also serves to distance herself from the reader as the use of formal language is considered a feature of expert speak (Lewis 2011; Van Leeuwen 2005; Fairclough 2000). MacQuitty moves between direct address, informal or conversational address and a more formal tone where she speaks in the third person. This leads to a more passive, fact-sharing form of communication, as evidenced in example (16), where the reader is not referred to or called on to engage with the text. Instead, information is given in a formal, text-book style. This puts MacQuitty in the role of teacher and the reader in the role of pupil, which could be considered an indication of her authority and the gap in status between her and her readership. By contrast, example (17) demonstrates how MacQuitty counters this with direct and conversational address taking on the role of the 'everyday' expert, much more akin to those described by Lewis (2011). 
Welch, Nikki and Ana Tominc (forthcoming): Is Wine Consumption in Britain Democratizing?

Communicating Class and Taste through the Saturday Times Wine Column (1982-2017). Social

Semiotics.

(16) "The region takes its name from one of the Ebro's tributaries, the Rio Oja, and is divided into three sub-areas...” 050584

(17) "Fed up with the prospect of another summer, swigging the same old, fat, buttery chardonnay or streamline, grassy Sauvignon Blancs? Relax - there is a new grape in town." 040502

Most of her writing is in a standard English, where the most commonly used conversational vocabulary could be described as belonging to an upper class informal or even out-dated lexicon. For example she uses the terms “...cares not a jot...” (041204), “...lashings of...” (041204), and "Bouquets to..." (031294) in the main body of the articles. These expressions give the sense of informality and friendliness, whilst at the same time carrying a potentially significant amount of linguistic capital because the nature of the language would not necessarily be the language used by the majority of her readers. ${ }^{7}$

The first-person voice adopted in the column extends towards an informal tone. Here the tone of the writing changes to not only draw the reader in but to engage them in having a shared negative

7 Commenting on eliteness of MacQuitty's language may not be a straight-forward task, not least because of lack of sociolinguistics studies into spontaneous use of upper class English (Britain 2017, 290). Contrary to general views about such elite language being equal to standard (RP) English and therefore, stable, available studies do find "structured variability as that found in the rest of society" as well as change through time (ibid.). Outdateness of her language may therefore have to do with the question of what constitutes elite language today given a shift away from traditional (old) elites towards new elites rooted in financial and managerial professions. 
Welch, Nikki and Ana Tominc (forthcoming): Is Wine Consumption in Britain Democratizing?

Communicating Class and Taste through the Saturday Times Wine Column (1982-2017). Social

Semiotics.

judgment or opinion, illustrated in (18) where she uses the inclusive collective pronoun 'us' alongside a derogatory description of 'them'. "Scrooges may be tempted, but the rest of us will want something much better in our festive glass." 021206

(19) "Few of us have homes with cellars..." 081290

By using this format she saves the face of the readership as she implies that the reader knows that the wine in question is not desirable and that anyone who had any taste would want to afford better. This technique increases throughout the period, suggesting the author is moving from a direct to a more subtle manner of command. Use of such language also suggests that while there is evidence that wine may be linguistically democratizing, much remains to be done to break the perception of a barrier that still constructs wine as the drink of specific groups. 
Welch, Nikki and Ana Tominc (forthcoming): Is Wine Consumption in Britain Democratizing?

Communicating Class and Taste through the Saturday Times Wine Column (1982-2017). Social Semiotics.

\section{Conclusion}

This analysis covers a period of dramatic change in wine consumption in the UK; between the 1970s and 2006, per capita wine consumption rose from less than 31 per head to over 261 per head, by which point $67 \%$ of the population considered themselves regular drinkers (Ritchie 2008). The variety of wines consumed has evolved from a starting point of traditional 'old world' wines to more accessible and varied sources and styles from around the world. Subsequently, however, consumption has plateaued and most recently declined as the health conscious younger generations drink less, but invariably buy more premium products. As a result, the industry faces an even greater challenge to communicate wine to their customer base in a way that engages and educates in an appealing way.

By understanding the socio-semiotics of wine communication, such as in the column under study, we start to unpick the ways in which the media influences understanding of wine and its choices through use of various language styles. As opposed to the more professionally used tasting notes that the general audience is normally not accustomed to, the media represents wine, its origin and taste through wine columns in terms that are more approachable for the ordinary consumer, thus encouraging identification and consumption of wine. Despite this wide-spread democratization over recent decades, we argue, wine remains at the same time a drink that still carries class distinction and is also constructed as such in the media; as MacQuitty writes of wine as an everyday drink of choice, she at the same time also continues to perpetuate the idea of wine as a divider between 'us' and 'them'. This may, as a consequence, support consumption patterns 
Welch, Nikki and Ana Tominc (forthcoming): Is Wine Consumption in Britain Democratizing?

Communicating Class and Taste through the Saturday Times Wine Column (1982-2017). Social

Semiotics.

where wine drinkers limit their wine choices to what they already know due to the constraint that results from the idea of the exclusiveness of certain wines.

We hope that this analysis usefully contributes to the way in which the wine industry communicates wine taste, thus further breaking down barriers in wine consumption. The research also contributes to the growing research on language and food, specifically in terms of food and lifestyle by stressing the critical discourse analysis perspective of everyday life topics. In this sense, this research also aims to contribute to bringing together social semiotics and food studies. 
Welch, Nikki and Ana Tominc (forthcoming): Is Wine Consumption in Britain Democratizing?

Communicating Class and Taste through the Saturday Times Wine Column (1982-2017). Social Semiotics.

\section{References}

Aitchison, J. 2012. Words in the mind: an introduction to the mental lexicon. Chichester: WileyBlackwell.

Bax, S. 2010. Discourse and genre: using language in context. Basingstoke: Palgrave Macmillan.

Bell, D., and J. Hollows. 2006. “Towards a history of lifestyle”. In Historicizing Lifestyle. Mediating taste, consumption and identity from the 1900s to 1970s, edited by D. Bell and J. Hollows. Aldershot: Ashgate.

Bender, J. 2008. "What the wine critics tell us". In Wine \& philosophy: A symposium on thinking and drinking, edited by F. Allhof. Malden: Blackwell, 125-136.

Bourdieu, P. 1977. Outline of a theory of practice. Cambridge, New York: Cambridge University Press.

Bourdieu, P. 1984. Distinction: a social critique of the judgement of taste. London: Routledge \& Kegan Paul.

Britain, D. 2017. Beyond the "gentry aesthetic": elites, Received Pronunciation and the dialectological gaze. Social Semiotics. 27(3): 288-298.

Caballero, R. and E. Suarez-Toste. 2008. "Translating the senses: teaching the metaphors in winespeak". In Cognitive linguistic approaches to teaching vocabulary and phraseology: Volume 6 of applications of cognitive linguistics, edited by F. Boers and S. Lindstromberg. Berlin: Mouton de Gruyter.

Caballero, R. 2007. Manner-of-motion verbs in wine description. Journal of Pragmatics. 39: 2095-2114. 
Welch, Nikki and Ana Tominc (forthcoming): Is Wine Consumption in Britain Democratizing?

Communicating Class and Taste through the Saturday Times Wine Column (1982-2017). Social Semiotics.

Crane, T. 2007. "Wine as an aesthetic object". In Questions of taste. The philosophy of wine, edited by Smith B. C. Oxford: Signal books, 141-156.

Creed, A. 2014. "Wine and metaphor: cross-cultural [dis]harmony". In Metaphors for, in and of education research, edited by W. Midgley, W., Trimmer, K. and Davies, A. Newcastle upon Tyne: Cambridge Scholars Publishing, 10-25.

Demossier, M. 2010. Wine drinking culture in France: a national myth or a modern passion? Cardiff: University of Wales Press. http://site.ebrary.com/lib/qmuc/detail.action?docID=10640642.

El Saj, H. 2012. Discourse analysis: personal pronouns in Oprah Winfrey hosting Queen Rania of Sweden. International Journal of Social Science and Humanity. 2: 529-532.

Eliot, C. 2006. Considering the connoisseur: probing the language of taste. Canadian Review of American Studies. 36 (2): 229-236.

Fairclough, N. 1989. Language and power. Essex: Addison Wesley Longman.

Fairclough, N. 1992. Discourse and social change. Oxford: Blackwell.

Fairclough, N. 2000. New Labour, new language. London: Routledge.

Fairclough, N. 2009. "A dialectical-relational approach to critical discourse analysis in social research." In Methods of Critical Discourse Analysis, edited by R. Wodak and M. Meyer, 162-188. London: Sage.

Fairclough, N. 2010. Critical discourse analysis. The critical study of language. Second edition. Harlow: Longman.

Gawel, R. 1997. The use of language by trained and untrained experienced wine tasters. Journal of Sensory Studies. 12: 267-284. 
Welch, Nikki and Ana Tominc (forthcoming): Is Wine Consumption in Britain Democratizing?

Communicating Class and Taste through the Saturday Times Wine Column (1982-2017). Social Semiotics.

Gerhardt, C., M. Frobenius and S. Ley (eds). 2013. Culinary linguistics. The chef's special. Amsterdam, John Benjamins Publishing Company.

Gluck, M. 2003. "Wine language: useful idiom or idiot speak". In New media language, edited by Aitchison, J. \& Lewis, $D$. Oxon: Routledge.

Hanke, R. 1989. Mass media and lifestyle differentiation: an analysis of the public discourse about food. Communication. 11: 221-238.

Harwood, N. 2005. 'We do not seem to have a theory... The theory I present here attempts to fill this gap': Inclusive and exclusive pronouns in academic writing. Applied Linguistics. 23(6): $343-375$.

Hommerberg, C. 2011. Persuasiveness in the discourse of wine: the rhetoric of Robert Parker. Doctoral dissertation. Linnaeus University.

Howland, P. 2013. Distinction by proxy: the democratization of fine wine. Journal of Sociology. 49: 325-340.

Johnston, J. and S. Baumann. 2010. Foodies: democratisation and distinction in the gourmet foodscape. Oxon: Routledge.

Joseph, R. 2009. The screen is more powerful than the pen. The Joseph Report. http://thejosephreport.blogspot.co.uk/2009/02/test.html.

Jurafsky, D. 2014. The Language of food. The linguist reads the menu. Norton.

Korsemeyer, C. 1999. Making sense of taste: food and philosophy. New York: Cornell University Press.

Lamont, M. 1992. Money, morals and manners. The culture of the French and American uppermiddle class. Chicago and London: The University of Chicago Press. 
Welch, Nikki and Ana Tominc (forthcoming): Is Wine Consumption in Britain Democratizing?

Communicating Class and Taste through the Saturday Times Wine Column (1982-2017). Social Semiotics.

Langlois, J., C. Dacremont, D. Peyron, D. Valentin, and D. Dubois. 2011. Lexicon and types of discourse in wine expertise: the case of vin de garde. Food Quality and Preference. 22: 491-498.

Leech, G. N. 1969. A linguistic guide to English poetry. Longman.

Lehrer, A. 2009. Wine and Conversation. Bloomington: Indiana University Press.

Lewis, T. 2008. Smart living: lifestyle media and popular expertise. New York: Peter Lang.

Lewis, Tania. 2010. "Branding, celebritization and the lifestyle expert." Cultural Studies 24 (4): $580-598$.

Machin, D. and T. van Leeuwen. 2003. Global schemas and local discourses in Cosmopolitan. Journal of Sociolinguistics. 7: 493-512.

Machin, D. and T. van Leeuwen, 2005. Language style and lifestyle: the case of global magazine. Media, Culture and Society, 27(4): 577-600.

Mapes, G. 2018. (De)constructing distinction: Class inequality and elite authenticity in mediatized food discourse. Journal of Sociolinguistics. 22 (3): 265-287.

Mautner, G. 2008. "Checks and balances: How corpus linguistics can contribute to CDA". In Methods of Critical Discourse Analysis, edited by R. Wodak and M. Meyer, 122-143. London: Sage.

Mennell, S. 1985. All manners of food: eating and taste in England and France from the middle ages to the present. Oxford, Cambridge, Mass: Blackwell.

Mouret, M., G. Lo Monaco, I. Urdapilleta, and W. Parr. 2013. Social representations of wine and culture; a comparison between France and New Zealand. Food Quality and Preference. 30: 102-107. 
Welch, Nikki and Ana Tominc (forthcoming): Is Wine Consumption in Britain Democratizing?

Communicating Class and Taste through the Saturday Times Wine Column (1982-2017). Social Semiotics.

Myers, G. 2004. Words in ads. London: Edward Arnold.

Naccarato, P. and K. LeBesco. 2012. Culinary aapital. London: Berg.

Nicholls, J. 2011. Wine, supermarkets and alcohol policy.

http://www.historyandpolicy.org/policy-papers/wine-supermarkets-and-alcohol-policy.

Noble, A. C. 1990/2002. Wine Aroma Wheel. http:// www.winearomawheel.com.

Peterson, R. and R. Kerns. 1996. Changing highbrow taste: from snob to omnivore. American Sociological Review. 61: 900-907.

Reichl, R. 2007. History in a glass: sixty years of wine writing from Gourmet magazine. New York: The Modern Library.

Reisigl, M., and R. Wodak. 2001. Discourse and discrimination: Rhetorics of racism and antisemitism. London, Routledge.

Riley, A. and K. Paugh. 2019. Food and language. Discourses and cultures across language. Routledge.

Ritchie, C. 2007. Beyond drinking: the role of wine in the life of the UK consumer. International journal of Consumer Studies. 31: 534 - 540.

Ritchie, C. 2011. Young adult interaction with wine in the UK. International Journal of Contemporary Hospitality Management. 23: 99 - 114.

Rousseau, S. 2012. Food media: celebrity chefs and the politics of everyday interference. London: Berg.

Shesgreen, S. 2003. Wet dogs and gushing oranges: Winespeak for a new millennium.

Chronicle review. http://chronicle.com/free/v49/i26/26b01501.htm. 
Welch, Nikki and Ana Tominc (forthcoming): Is Wine Consumption in Britain Democratizing?

Communicating Class and Taste through the Saturday Times Wine Column (1982-2017). Social Semiotics.

Silverstein, R. 2004. Cultural concepts and the language-culture nexus. Current Anthropology. 45: 621-652.

Tannen, Deborah F. 1987. Conversational style. In Psycholinguistic models of production, edited by Hans W. Dechert \& Manfred Raupach. Norwood, NJ: Ablex, pp. 251-267.

Tominc, A. 2017. The discursive construction of class and lifestyle. Celebrity cookbooks in postsocialist Slovenia. Amsterdam: John Benjamins.

Van Leeuwen, T. 2005. Introducing social semiotics. London: Routledge.

Warde, A. 1997. Consumption, food and taste: Culinary antinomies and commodity culture. London: Sage.

Wehring, O. 2012. Comment - London International Wine Fair; the knives are out. Again. Just Drinks, 13 March 2012.

WSET. 2014. The systematic approach to tasting wine. London: WSET. http://www.wsetglobal.com/documents/dip_sat_wine2014_v2.pdf 